\title{
The state of agricultural landscapes in the Mediterranean: smallholder agriculture and land abandonment in terraced landscapes of the Ricote Valley, southeast Spain
}

\author{
Katharina Heider ${ }^{1}$ [D $\cdot$ Juan Miguel Rodriguez Lopez ${ }^{1} \cdot$ Andrea L. Balbo $^{2} \cdot J_{\text {ürgen Scheffran }}{ }^{1}$
}

Received: 11 June 2020 / Accepted: 16 December 2020 / Published online: 17 February 2021

(C) The Author(s) 2020

\begin{abstract}
The fast and broad adoption of mechanization and chemical inputs in Mediterranean terraced agriculture, combined with warming climate trends, has led to the progressive degradation of environmental and social conditions. These factors have concurred with the increasing abandonment of smallholder agriculture. We aimed to detect and quantify the progression of cultivated and abandoned terraced fields in the Ricote Valley between 2016 and 2019 while also exploring reasons for land abandonment over the past decades. To quantify cultivated and abandoned agricultural terraces, we conducted (1) a terrace detection based on Lidar and cadaster data, (2) a land use classification based on Sentinel imagery, and (3) an investigation of the reasons for land abandonment based on participant observation and an expert survey. Our results show high rates of abandonment compared to the total available agricultural terraced area in the Ricote Valley. In 2016, 56\% of the detected terraced area was classified as not cultivated. In 2019, the percentage decreased to $40 \%$. Small parcels are cultivated to a higher percentage than large or medium-sized parcels. We identified five main reasons underlying land abandonment: (1) low income of farmers; (2) land fragmentation resulting in higher transaction costs; (3) lack of interest in agricultural activities among young generations; (4) lack of modernization; and (5) emotional bonds preventing the sale of abandoned parcels. We stressed the importance of a placebased mixed method approach to gain a comprehensive understanding of the specificities of a given research area.
\end{abstract}

Keywords Cultural landscape $\cdot$ Multifunctionality of agriculture $\cdot$ Land fragmentation $\cdot$ Geographic information system $\cdot$ Mixed method $\cdot$ Remote sensing

Communicated by Wolfgang Cramer

Katharina Heider

katharina.heider@uni-hamburg.de

Juan Miguel Rodriguez Lopez

miguel.rodriguez@uni-hamburg.de

Andrea L. Balbo

kofibab@gmail.com

Jürgen Scheffran

juergen.scheffran@uni-hamburg.de

1 Research Group Climate Change and Security (CLISEC), Institute of Geography and Center for Earth System Research and Sustainability (CEN), Center for Sustainable University (KNU), University of Hamburg, Grindelberg 5, 20144 Hamburg, Germany

2 Laboratory of prehistoric archaeology and anthropology (LAP) Institute of Environmental Sciences, University of Geneva, Boulevard Carl Vogt 66, CH-1211 Geneva, Switzerland

\section{Introduction}

Terraced smallholder agriculture is an important component of Mediterranean landscapes. It represents the outcome of the long-term convergence of human and environmental trajectories, resulting in a social-ecological system that has proven its stability and resilience over the past ten centuries or more (Balbo et al. 2016, 2020; Blondel 2006; Lasanta et al. 2017a). However, since the 1940s, European agriculture has developed increasingly towards industrial, corporate, and globalized structures (Altieri and Nicholls 2012; Chemnitz 2019; European Commission 2019; Reynolds et al. 2014). The expansion and common practices of industrial agriculture, such as the use of monocultures dependent on high inputs of chemical fertilizers and pesticides, combined with warming climate trends and increasing water scarcity, have led to deteriorating environmental and social conditions and the 
homogenization of agricultural landscapes (Cramer et al. 2018; Endenburg et al. 2019; German National Academy of Sciences Leopoldina 2018; IAASTD 2009; Kurz 2018; Lefebvre et al. 2015; Springmann et al. 2018; Plieninger et al. 2006; Vicente-Serrano et al. 2014). These factors have concurred with an increasing abandonment of smallholder agriculture over the past decades (Chemnitz 2019; European Commission 2019; Lasanta et al. 2017b; Lomba et al. 2019).

In the literature, different perspectives on land abandonment are presented. Some scholars described land abandonment as an opportunity while others understood it as a threat (Otero et al. 2015). Land abandonment often occurs in mountainous and remote areas and is generally associated with the loss of biodiversity (i.e., species adapted to human-made environments), increased risk of fires, soil erosion, loss of cultural, aesthetic, and historical values, as well as the loss of traditional ecological knowledge (Barthel et al. 2013; Gómez-Baggethun et al. 2013; van der Zanden et al. 2018; Zagaria et al. 2018). However, benefits that may be gained from land abandonment include passive revegetation, active reforestation, water regulation, soil recovery, nutrient cycling, and increased biodiversity (Rey Benayas et al. 2007; Zaragozí et al. 2011). Socio-economic factors have been described as the principal drivers of land abandonment, having a greater impact than environmental factors (Rey Benayas et al. 2007). However, climate has been identified as the most important environmental driver in southeast Spain (Alonso-Sarría et al. 2016). Moreover, Lasanta et al. (2017a, b) identified the Common Agricultural Policy (CAP) of the European Union $(E U)$ as one of the main drivers of land abandonment in the EU member states. In arid and semi-arid regions of southern Europe, decades of intensive cultivation and irrigation have led to soil degradation and further increased land abandonment (Lasanta et al. 2017b). Because of these and other negative externalities of current agricultural practices, an increasing number of authors are calling for changes in the current agricultural system and challenging the productivity paradigm (Altieri and Nicholls 2012; Bernard and Lux 2017; Freibauer et al. 2011; Hathaway 2016; IAASTD 2009; IPES-FOOD 2016; Lomba et al. 2019; Reynolds et al. 2014; WBGU 2011).

Given this context, we explored recent trends of smallholder agriculture in the Ricote Valley. We examined cultivation and land abandonment in a study region still dominated by smallholder agriculture. This study aims to detect and quantify actively used and abandoned terraced fields in the Ricote Valley over the period of 2016-2019 while also exploring reasons for land abandonment over the longer period (i.e., 1940s to present). This aim led to the following research questions:

1. What is the state of smallholder agriculture in the Ricote Valley?
2. How much of the traditional terraced agriculture in the Ricote Valley was not cultivated between 2016 and 2019 ?

3. What are the reasons for the observed land abandonment over the past decades?

We used GIS-based analyses to detect agricultural terraces and quantify land cultivation and abandonment in the traditional orchards of the Ricote Valley. Using spatial analysis and place-based research methods, i.e., expert survey and participant observation, we explored the reasons for the abandonment of terraces combining quantitative and qualitative research methods.

The term "abandoned" is used as equivalent to "not cultivated." We define the "traditional" agricultural area as the area that integrates local historic and cultural agricultural elements and has been established over decades to centuries. Examples for local historic and cultural agricultural elements are terraces, gravity-based flood irrigation, rainfed cultivation, stone walls, local crops, integration of livestock, and little mechanization. Nowadays, some of these elements have been substituted by conventional modern agricultural elements (e.g., monoculture, chemical inputs) in the study area.

\section{The study area: smallholder agriculture in the Ricote Valley and its multiple functions}

The study area includes the traditional orchards of the Ricote Valley and is part of the Segura river basin located in the region of Murcia in southeast Spain. The climate in the study area is semi-arid with strong seasonality. The studied orchards are spread across seven villages: Abarán, Blanca, Ojós, Ricote, Ulea, Villanueva, and Archena (Fig. 1). This region contains a hydraulic system, which was introduced by Amazigh Berber populations more than 1000 years ago (Puy and Balbo 2013). Agricultural terraces are a central element of the hydraulic system. These terraces were constructed using stonewalls, and small canals between the terraces are used for flood irrigation. Drip irrigation has partially substituted traditional irrigation techniques over the past 12 years (García Avilés 2014; Puy et al. 2016). The primary crop planted on the terraces is lemon, followed by olive, almond, and a variety of fruits. The agricultural land is highly fragmented due to the traditional heritage system in this region, which mandates that parts of land are granted to all siblings within a family. Smallholder family farming remains the most widespread form of farming in this area to the present day. Generally, farming activities on lands smaller than 2 ha are defined as small-scale farming (Jouzi et al. 2017), which is the case for most agricultural activities in the Ricote Valley.

Agriculture serves various functions for the environment, society, and economy of the Ricote Valley: traditional smallholder agriculture involves greater biodiversity of species 

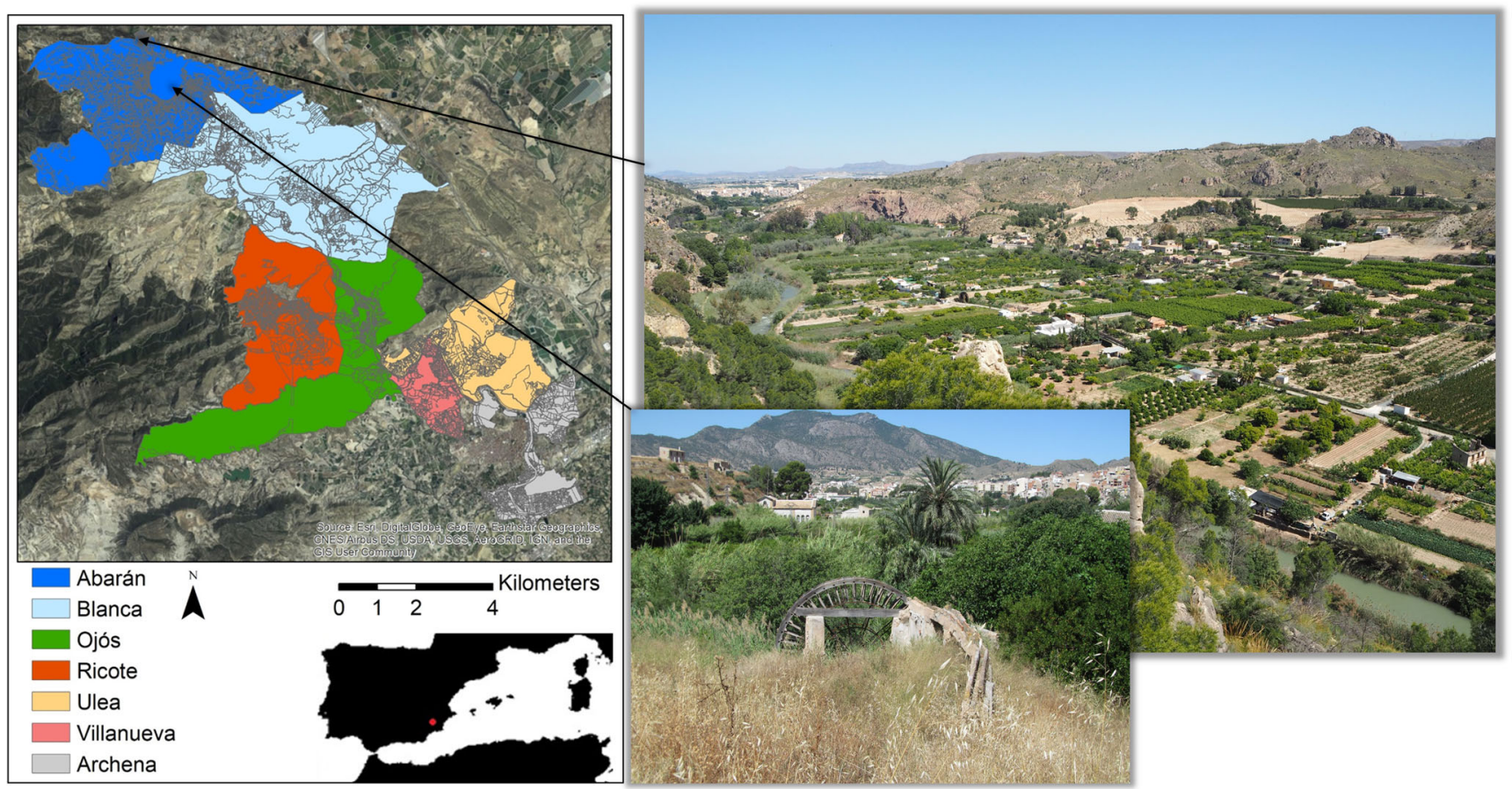

Fig. 1 The study region: Ricote Valley, Murcia (map); traditional orchards, Abarán (above); parcel without cultivation for a long time, Abarán (below) (Photos: Heider)

adapted to the human-made environment compared with industrial agriculture due to its small parcel sizes, diversity of microhabitats, and variety of cultivated crops such as lemon, olive, almond, peach, and vegetables. Additionally, a low degree of mechanization produces lower emissions and less air pollution. Furthermore, nature and wildlife protection is supported in the study area due its participation in the Natura 2000 network (Región de Murcia 2017).

From a social perspective, traditional smallholder agriculture provides space for recreation. Furthermore, local heritage is preserved in the forms of traditional agricultural systems, traditional irrigation technologies (e.g., hydraulic systems and water wheels), traditional agricultural practices, and traditional ecological knowledge (Bravo Sánchez 2018; Gil Meseguer 2014; Puy and Balbo 2013).

From an economic perspective, smallholder agriculture is a source of food security, income, and employment in the Ricote Valley (García Avilés 2000, 2014). Often, agriculture represents an additional income source for families (pluriactivity), increasing their resilience to price volatility of the production. Moreover, the cultural landscape shaped by smallholder agriculture attracts tourists, opening new income opportunities.

We selected the study region because it is a multifunctional (agri)cultural landscape dominated by smallholder agriculture. Moreover, the study region is dominated by terraced agricultural landscapes, which could become a hazard if abandoned (Tarolli et al. 2014), and the broader Murcia region is severely affected by land abandonment (Alonso-Sarría et al. 2016). However, our study region represents one case of a broad range of European landscapes threatened by land abandonment or land use intensification (Lomba et al. 2019).

Despite the high value of the various functions of smallholder agriculture, European statistics show that small-scale agriculture has deteriorated in recent years. Between 2003 and 2013, one-third of European farms were abandoned and smallholder farmers with family enterprises have been substituted by large companies (Alonso-Sarría et al. 2016; Chemnitz 2019). In the following sections, we discuss whether a similar trend can be identified in the study area.

\section{Data and methods}

To research the state of smallholder agriculture in the Ricote Valley, we used GIS-based analyses to detect agricultural terraces and quantify land cultivation and abandonment in the traditional orchards of the Ricote Valley. We implemented a three-step approach. First, we located traditional agricultural terraces and, second, determined if they were cultivated. Third, we quantified cultivated and abandoned agricultural terraces in the years 2016 until 2019. Furthermore, we investigated the reasons for land abandonment using spatial analysis to include parcel sizes and place-based research methods (Reynolds et al. 2014), i.e., participant observation and an expert survey, to include local and expert knowledge. 
Phase 1

quan

Geo data analysis
Phase 2

Phase 3

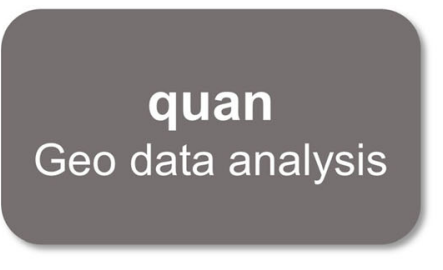

\section{- Quantification of land abandonment}
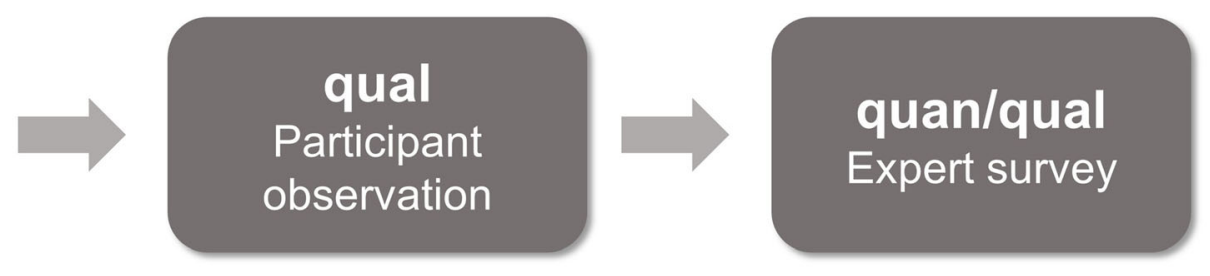

\section{- Identification of reasons for land abandonment}

- Quantification of identified reasons (quan)

- Identification of additional reasons (qual)

Fig. 2 Mixed method research design combining quantitative methods (quan) and qualitative methods (qual)

The mixed method research design is shown in Fig. 2. The sequential 3-phase design combines an explanatory design (phases 1 and 2) to deepen the findings of the quantitative geo data analysis about land abandonment with an exploratory design (phases 2 and 3 ) to identify reasons for land abandonment and quantify them. In the third phase, we integrated quantitative and qualitative data using the reasons identified during participant observation for the expert survey. The priority is given to quantitative research methods (Kuckartz 2014).

\section{Data and preprocessing}

The GIS analysis is based on cadaster data; a Digital Elevation Model (DEM, $2 \times 2 \mathrm{~m}$ ), which was calculated using Lidar point clouds from 2016; and satellite imagery. As satellite images, we used Sentinel data with a resolution of $10 \times 10 \mathrm{~m}$. For the analysis, we selected the months May and June for all available years, 2016 until 2019, of the Sentinel sensor. All data is freely available. We used SAGA-GIS and ArcGIS to conduct the analysis. For field validation, we used ArcGIS Online and the ArcGIS Collector App.

Cadaster data and Lidar point clouds need various steps of preprocessing. Cadaster data for the Ricote Valley is provided by the Spanish authorities (Ministerio de Hacienda 2020). Based on local expert knowledge, we included only the zones of traditional orchards in the cadaster data of every village for further analysis. Urban areas, as well as rivers and streets, were excluded.

High-resolution Lidar point clouds and Sentinel data can be downloaded free of charge (Instituto Geográfico Nacional 2019; USGS 2019). We conducted the preprocessing of point clouds in SAGA-GIS (Conrad et al. 2015). The point clouds have a mean point distance of $0.44 \mathrm{~m}$. We merged and converted them to raster data with a grid size of $2 \times 2 \mathrm{~m}$. Gaps in data were filled using the tools "shrink and expand" and "spline interpolation." A Digital Surface Model (DSM) was created. In order to create a DEM, we excluded small structures like trees and bushes of the DSM using a morphological filter with a radius of $4 \mathrm{~m}$ ( 2 cells). The DSM and DEM were cut to the extent of the study area using the selected zones of the cadaster data.

\section{Terrace detection}

The terrace detection is based on location (cadaster) and planarity of parcels (DEM). Spanó et al. (2018) tested different detection methods for terraces in Italy and their regional-scale approach using DEMs and cadastral maps represents a good fit to our data availability. We adapted the procedure to our study area. First, we transferred the elevation values (z-values) of the DEM to the polygon vertices of the cadaster data. Second, we calculated the standard deviation for the $\mathrm{z}$ values per polygon in order to determine the planarity of a parcel. We set the threshold for the calculated planarity to 11.8. If polygons had a planarity value below or equivalent to 11.8 , they were classified as terrace. If the value was larger, they were excluded. The planarity values and the usage as terrace are highly dependent on the study area and can vary from village to village. We set the threshold at 11.8 because it produced the best results excluding most of the rugged terrain and including almost all terraces in every village. As an additional parameter for terrace detection, Spanó et al. (2018) used the slope index. For our study area, the use of a slope index did not alter the results. One polygon in the cadaster data can consist of only one terrace containing almost no slope or various terraces containing very high slopes. This reduced the usability of the slope index for terrace detection in the study region. In consequence, we excluded it from the terrace detection procedure. 


\section{Land use classification}

After the terrace detection, we classified the cultivation status of every parcel to cultivated or not cultivated. We used two different classification methods to determine if parcels were cultivated or not. The first method is based on Lidar data, calculating the plant height. The second method is based on Sentinel images using the Normalized Difference Vegetation Index (NDVI) to determine plant health.

To determine the plant height with Lidar data, we used the difference between the beforehand calculated DSM (including plants) and the DEM (excluding plants) to create a surface model of the plants in the study region. In the next step, we classified the plant height according to our needs. The main crops in the study area are lemons and olives. In consequence, we focused on tree heights of up to $3.5 \mathrm{~m}$ as this is the maximum height of trees in the study area, to facilitate the picking of fruits. Higher trees are mainly forests or parcels that are no longer in use. As minimum height, we used $0.25 \mathrm{~m}$ including young trees. The classification of plants based on Lidar data can be seen in Fig. 3 (left). The map shows a classification of
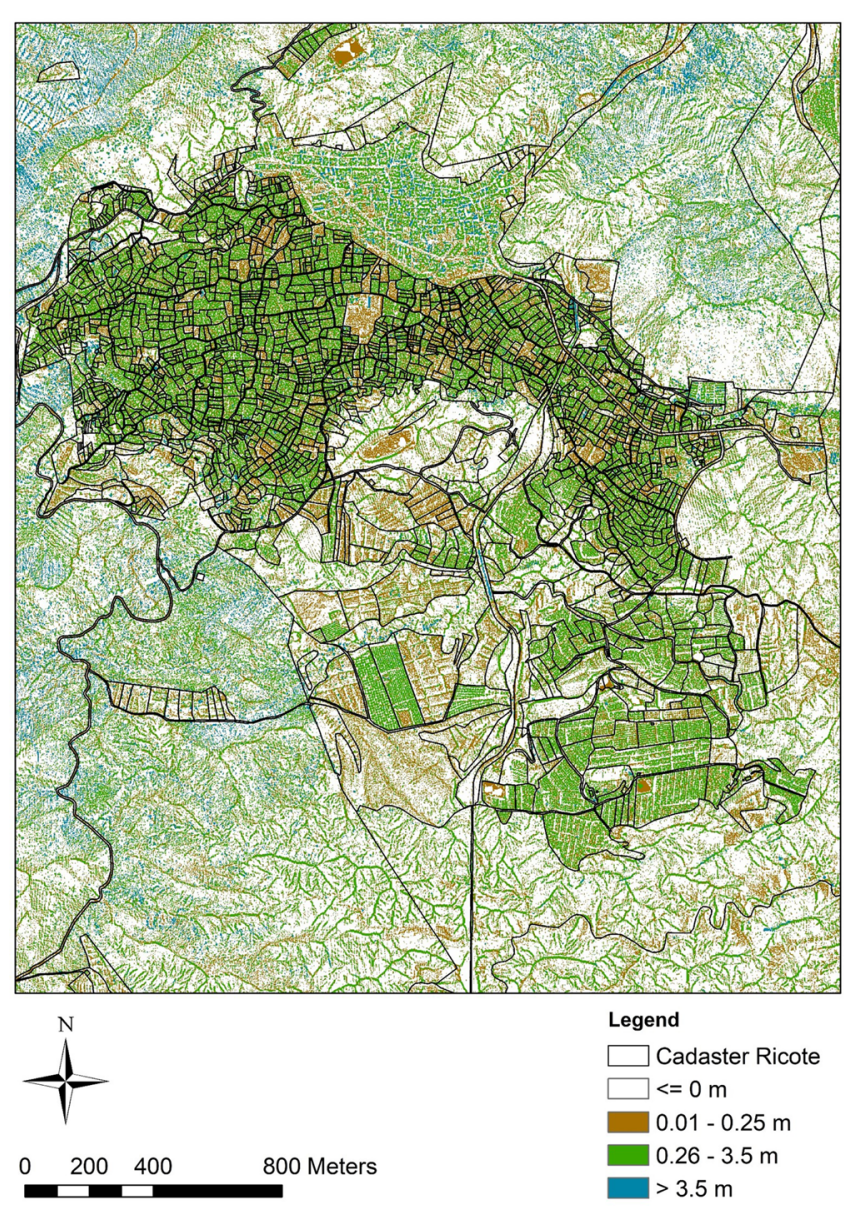

Fig. 3 Land use classification based on Lidar data in Ricote village. The use of agricultural parcels is based on plant heights. Brown, heights lower than local tree plantations; green, possible tree plantation heights; blue, plant heights in Ricote. Green parcels are cultivated; brown and blue parcels are not cultivated. In the following, the cultivation per parcel was calculated and quantified using the "zonal statistics" tool in ArcGIS. The results were cut to the extent of the detected terraces.

As an alternative approach to the land use classification based on Lidar, we used the NDVI based on satellite data from Sentinel.

The NDVI is calculated using the following formula:

$\mathrm{NDVI}=\frac{N I R-\text { red }}{N I R+\text { red }}$

where NDVI is the Normalized Difference Vegetation Index, NIR is near infrared (Sentinel: band 8), and red is the red band (Sentinel: band 4).

The NDVI for Ricote can be seen in Fig. 3 (right). In the following, we set a threshold for the differentiation between cultivated and not-cultivated parcels at 0.3 adapted to Mediterranean tree crops between April and August (Bendetti et al. 1994). We calculated and quantified the cultivation per parcel using "zonal statistics" in

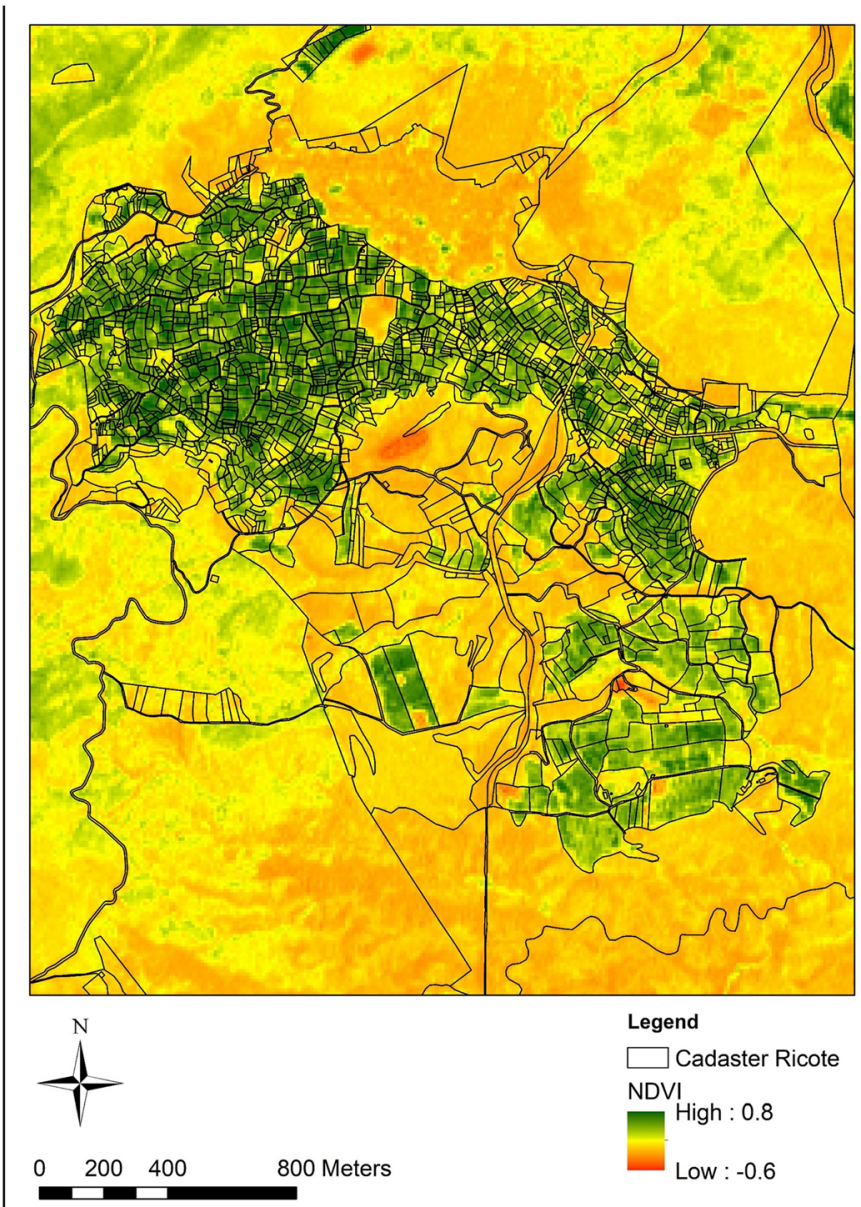

heights higher than local tree plantations (left). Normalized Difference Vegetation Index based on Sentinel data in Ricote village. Green, healthy vegetation (right) 
ArcGIS and cut the results to the extent of the detected terraces. We conducted the procedure for the years 2016 until 2019. The working steps of terrace detection and land use classification based on Sentinel data can be seen in Fig. 4.

For the accuracy assessment, we conducted a preliminary assessment in the first step using high-resolution satellite imagery of Google Earth comparing Lidar (2016) and Sentinel classification results (2016-2019) (See et al. 2015). In the second step, we validated the results locally in the orchards of the seven villages in the Ricote Valley in summer 2019. For the validation, we created 100 random points according to our two classification classes (Lillesand et al. 2004). In the next step, we uploaded the validation points to ArcGIS Online and used the ArcGIS Collector App to validate and edit the data locally in the study region. Due to the construction of fences in the study region, we were not able to validate all points. The results of the validation are shown in a confusion matrix, based on which we calculated the producer's accuracy, the user's accuracy, and the accuracy rate (Story and Congalton 1986).

Producer's Accuracy $=\frac{C C}{C T}$

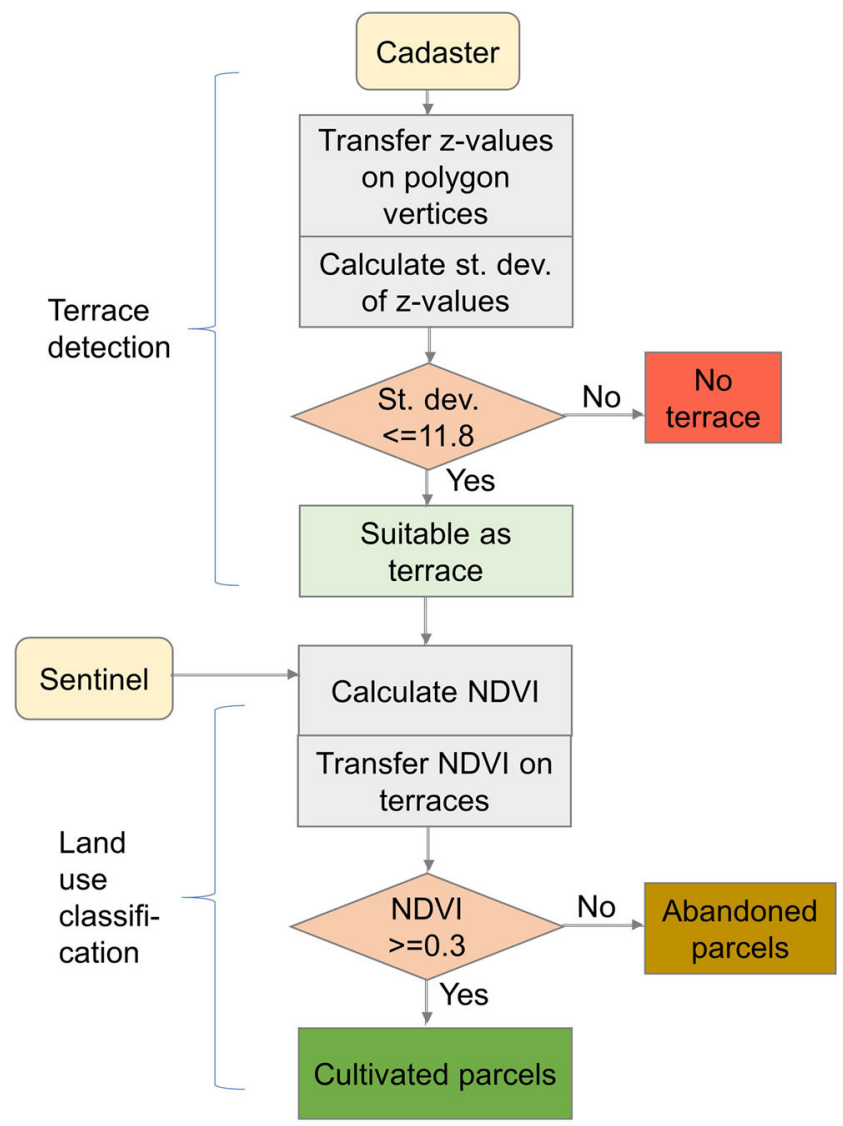

Fig. 4 Workflow of GIS analysis: terrace detection (above) and land use classification (below) to identify cultivated and not-cultivated parcels where $C C$ is the number of correctly classified samples of one category and $C T$ is the column total, which represents the total number of reference samples of one category.

User's Accuracy $=\frac{C C}{R T}$

where $C C$ is the number of correctly classified samples of one category and $R T$ is the row total, which represents the total number of samples that were classified in one category.

Accuracy Rate $=\frac{T P+T N}{N}$

where $T P$ is true positive (actual cultivated and classified cultivated), $T N$ is true negative (actual not cultivated and classified not cultivated), and $N$ is the total number.

\section{Exploring the reasons for land abandonment}

In the next step, we explored the multivariate reasons for land abandonment in the study region. Using two separate approaches, we conducted a spatial analysis based on parcel sizes and we used participant observation and expert surveys in the study region to identify the most important reasons. To research the abandonment of parcels according to different parcel sizes, we classified parcels in three quantiles to determine small $\left(<556 \mathrm{~m}^{2}\right)$, medium-sized $\left(556-1533 \mathrm{~m}^{2}\right)$, and large parcels $\left(>1533 \mathrm{~m}^{2}\right)$. In the next step, we calculated the absolute and relative cultivated and not-cultivated area for every class and year of analysis. Moreover, we calculated how much of the total cultivated and not-cultivated land was covered by small, medium-sized, or large parcels.

Giving voice to the local people, participant observation and expert surveys enabled the integration of local perspectives to better understand the research results. During participant observation in the field, we participated in agricultural activities, communicating regularly with local stakeholders (Thomas 2019). Insights from participant observation supported by a literature review enabled the preselection of reasons for land abandonment used in the expert survey. We selected the experts on the basis of their expertise on the topic, location, and their availability. Eleven experts with scientific, economic, and administrative backgrounds participated in the survey. In personal interviews in June 2019, the experts were requested to evaluate the importance of preselected reasons for the abandonment of parcels in the Ricote Valley on a scale from 0 (not important) to 4 (very important), and they could also add other reasons. In the evaluation process, first, we created new categories that combined the preselected and added reasons; second, we calculated the weighted arithmetic mean of the new categories, considering the number of persons mentioning each added reason; finally, we only included reasons with a value higher than 2 (moderate importance). 


\section{Results}

We found high rates of agricultural land abandonment within the terraced fields of the Ricote Valley. Figure 5 shows the dynamics of abandonment and cultivation of parcels between 2016 and 2019. Parcels are marked in red if they are classified as cultivated in 2016 and as not cultivated in 2019. Parcels are marked in green if they are classified as not cultivated in 2016 and as cultivated in 2019. Yellow parcels indicate no change. The map shows more green parcels than red parcels, which corresponds to the calculated increase of cultivated area in the Ricote Valley over the 2016-2019 period. Furthermore, the largest agglomerations of new cultivated areas are observed mainly in Abarán, Villanueva, and Archena. The mean percentage of abandonment of agricultural area between 2016 and 2019 is $51.35 \%$. In other words, more than half of the agricultural terraced land available in the Ricote Valley was not cultivated on average in the 2016-2019 period. The abandonment varies between years. While the percentage of abandonment in the first year of the analysis was $56.33 \%$ (2016), the percentage decreased in the following years to $55.01 \%$ in 2017, 54.12\% in 2018, and 39.94\% in 2019 (Table 1). Thus, in 2019 , with a difference of $14.18 \%$ in comparison to 2018 , much less abandoned area is detected. 2019 marks the year where the detected percentage of cultivated area $(60.06 \%)$ is higher than the abandoned area (39.94\%). After the description of the accuracy assessment, we will describe the detected reasons for abandonment including an analysis of parcel sizes.

In the preliminary accuracy assessment using highresolution satellite imagery of Google Earth, we found a higher accuracy of land use classification based on Sentinel data than based on Lidar data. In the next step, we validated the classification results based on Sentinel imagery of 2019 locally. The field validation was conducted in summer 2019 and the results are shown in a confusion matrix. The confusion matrix illustrates the performance of the land use classification using predicted and actual classes of cultivated and notcultivated parcels (Table 2). The producer's accuracy shows that $89 \%$ of cultivated parcels are classified correctly, while only $44 \%$ of not-cultivated parcels are classified correctly.

Table 1 Quantification of the cultivated (C) and not-cultivated (NC) area in the Ricote Valley between 2016 and 2019

\begin{tabular}{lllll}
\hline Year & $\begin{array}{l}\mathrm{NC} \\
\text { area }\left(\mathrm{m}^{2}\right)\end{array}$ & $\begin{array}{l}\mathrm{NC} \\
\text { area }(\%)\end{array}$ & $\begin{array}{l}\text { C } \\
\text { area }\left(\mathrm{m}^{2}\right)\end{array}$ & $\begin{array}{l}\text { C } \\
\text { area }(\%)\end{array}$ \\
\hline 2016 & $12,728,791.06$ & 56.33 & $9,868,456.88$ & 43.67 \\
2017 & $12,430,678.88$ & 55.01 & $10,166,569.07$ & 44.99 \\
2018 & $12,230,382.72$ & 54.12 & $10,366,865.23$ & 45.88 \\
2019 & $9,024,215.62$ & 39.94 & $13,573,032.33$ & 60.06 \\
\hline
\end{tabular}

The user's accuracy shows a probability of $78 \%$ for a parcel classified as cultivated to be actually cultivated on the ground. The probability for not-cultivated parcels is $65 \%$. The overall accuracy rate is 0.753 .

In the following, we describe the reasons for land abandonment. The analysis of abandonment according to parcel size shows that the percentage of cultivated area decreases with an increasing parcel size (Fig. 6). Parcels were categorized as small if they had an extent of up to $556 \mathrm{~m}^{2}$, as medium with an expansion of 556 until $1533 \mathrm{~m}^{2}$, and as large with more than $1533 \mathrm{~m}^{2}$. Small parcels are cultivated to a higher percentage than large or medium-sized parcels. The mean cultivated area of small parcels between 2016 and 2019 was $66.20 \%$, while the mean cultivated area of large parcels was $45.68 \%$. The mean cultivated area of medium-sized parcels lied in between with a value of $58.83 \%$. In $2019,76 \%$ of the agricultural area of small parcels was cultivated, while only $57 \%$ of the area of large parcels was cultivated. The percentage of cultivation increased between 2016 and 2019 for all parcel sizes and the largest increase in cultivation can be seen between the years 2018 and 2019 with an increase of over $10 \%$ for all parcel size categories.

Based on a complementary calculation, Table 3 shows the percentage of total cultivated and not-cultivated land within small, medium-sized, and large parcels in 2016 and 2019, respectively. The cultivated area of large parcels covered c. $75 \%$ of the total cultivated land in 2016, while the cultivated area of medium-sized parcels covered c. $18 \%$, and the cultivated area of small parcels covered c. $7 \%$ of total cultivated land. For not-cultivated land, we see a similar distribution. The not-cultivated area of large parcels covered c. $85 \%$ of total not-cultivated land in 2016, while the not-cultivated area of medium-sized parcels covered c. $12 \%$, and the not-cultivated area of small parcels covered c. $3 \%$ of total not-cultivated land. Between 2016 and 2019, the percentage of cultivated and not-cultivated areas covered by small and medium-sized parcels decreased, while the percentage of cultivated and notcultivated areas covered by large parcels expanded (Table 3 ).

According to the expert survey, the most important reasons for the abandonment of agricultural land in the Ricote Valley are socio-economic: (1) the low income of farmers, which is related to the current market situation and derived from competition with large-scale industrial agriculture in the surrounding area; (2) land fragmentation, which causes higher transaction costs for farmers; and (3) the lack of interest for agricultural activities among young generations. This is revealed in the high average age of farmers and the phenomenon of ruralurban migration, contributing to the depopulation of rural areas; (4) the lack of modernization is mentioned as a challenge that prevents agricultural farms in the Ricote Valley to compete with the industrial agriculture in the surrounding area; and (5) emotional bonds to agricultural land due to family farming history prevent the sale of abandoned parcels. 
Fig. 5 Cultivation and abandonment in the Ricote Valley between 2016 and 2019; red parcels, change to not cultivated; green parcels, change to cultivated; yellow parcels, no change between 2016 and 2019

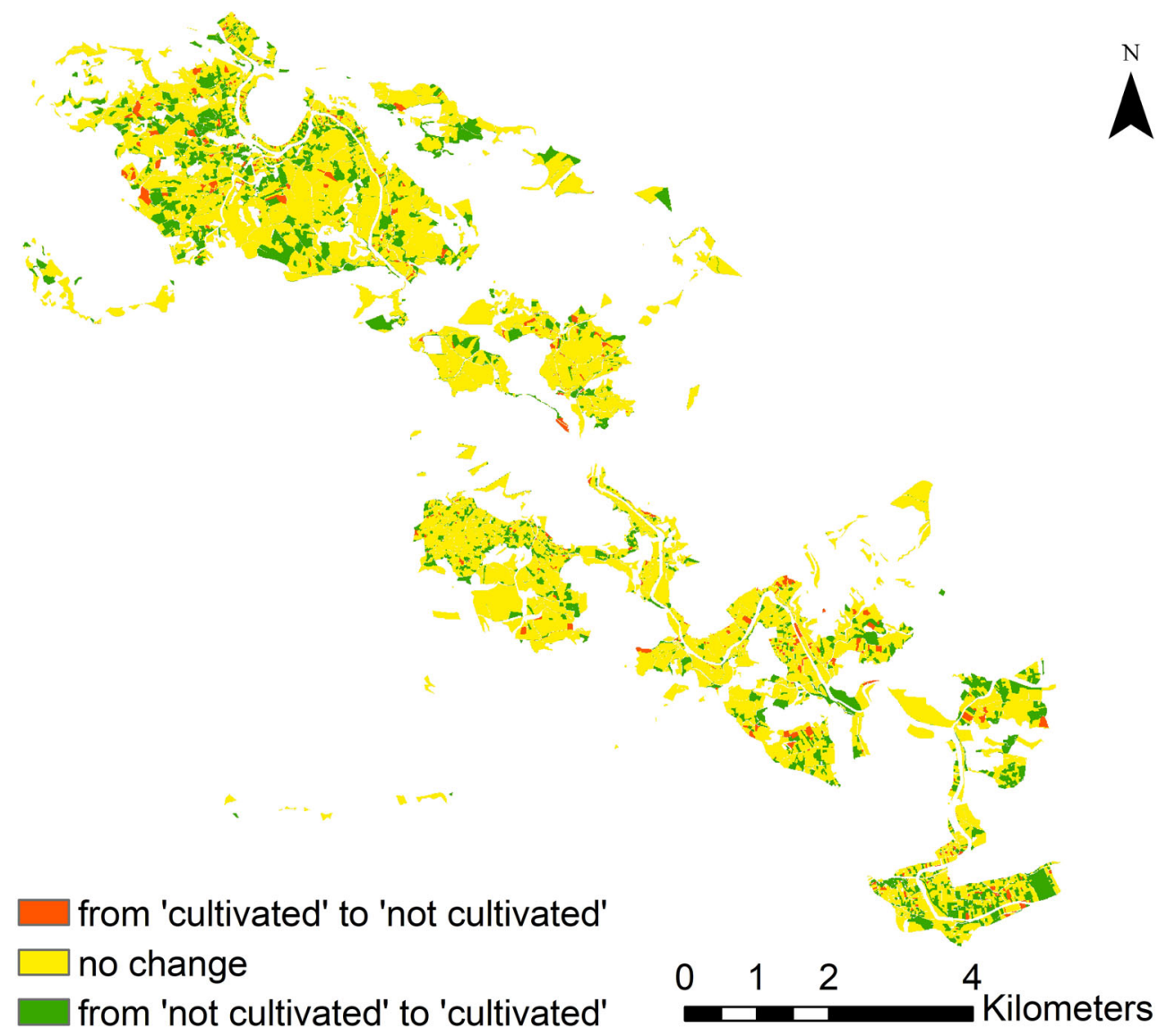

\section{Discussion}

The GIS analysis has shown that a large percentage of the detected terraced area is not cultivated in the Ricote Valley. However, the cultivated area has increased during the last years, especially between 2018 and 2019. In particular, small parcels were found to be cultivated to a higher percentage than large or medium-sized parcels. In 2018, the percentage of cultivated area in small parcels was $22 \%$ higher than the percentage of cultivated area in large parcels (Fig. 6). Thus, smaller-scale agriculture seems to be more intact than largerscale agriculture in the Ricote Valley. One explanation is the long tradition of family farming in the Ricote Valley. Most of the small agricultural parcels are cultivated by families, where the agricultural activity is not the main income source. In these cases, smallholder agriculture tends to be less vulnerable to price volatility and economic shocks. Nevertheless, like in most European regions (Chemnitz 2019), the agricultural area covered by small and medium-sized parcels decreased between 2016 and 2019, while the agricultural area covered by large parcels expanded.

The experts' perceptions captured by the questionnaire have revealed various reasons for the high percentage of abandonment of detected terraces in the Ricote Valley. Socioeconomic dimensions emerged as the most important reasons for land abandonment. Most of the terraced fields in the study area are relatively small, with $2 / 3$ of the detected terraces having an extension of less than $1533 \mathrm{~m}^{2}$. Thus, the topography of the Ricote Valley seems to have limited the uptake and expansion of industrial agriculture in the traditional orchards. However, the competition with industrial agriculture is omnipresent in the conversation with locals and experts. The Ricote Valley is surrounded by large-scale agriculture and crop prices are volatile, as they are determined by the European market and the large supply. Most EU subsidies are distributed according to the agricultural area under cultivation, which supports mainly large-scale farms (Chemnitz 2019; IPES-FOOD 2016). According to personal communications and explanations obtained from the questionnaire, many parcels in the Ricote Valley are too small to receive any helps from the European Common Agricultural Policy. This explains the low income of farmers and the current market situation as important reasons for land abandonment.

According to the experts, another important reason for abandonment was land fragmentation. The high land fragmentation in the study area is determined by geographical and cultural factors. On the one hand, the steep topography, in which agricultural parcels are located, limits the possibilities to merge smaller parcels into larger ones. On the other hand, the local heritage system based on Muslim traditions imposes 
Table 2 Confusion matrix showing the validation of land use classification results for cultivated (C) and not-cultivated (NC) parcels based on Sentinel 2019.

We conducted the validation for a total of 81 parcels in summer 2019

\begin{tabular}{llllll}
\hline & & Field validation & & & \\
\cline { 3 - 4 } & & Actual "C" & $\begin{array}{l}\text { Actual } \\
\text { "NC" }\end{array}$ & Row total & User's accuracy \\
\hline Classified & Predicted "C" & 50 & 14 & 64 & 0.78 \\
& $\begin{array}{l}\text { Predicted } \\
\text { "NC" }\end{array}$ & 6 & 11 & 17 & 0.65 \\
& Column total & 56 & 25 & 81 & \\
\hline & Producer's accuracy & 0.89 & 0.44 & & \\
\hline
\end{tabular}

the subdivision and inheritance of land among siblings. Land fragmentation was mentioned in the expert survey as an economic and management challenge that causes high transaction costs (Heider et al. 2018) and prevents further mechanization and industrialization of agriculture. However, land fragmentation is highly related to biodiversity, protection from winds and erosion, and to the cultural landscape that was shaped in the region over 1000 years or more (Bentley 1987; Blondel 2006; Crecente et al. 2002; Puy and Balbo 2013). Reducing land fragmentation by changing the physical structure of the agricultural area would possibly result in the deterioration of this cultural landscape, eroding the multiple values and functions of agriculture in the Ricote Valley. Furthermore, the spatial analysis showed that small parcels are cultivated at a higher percentage than large or medium-sized parcels and thus tend to be less vulnerable.

Importance was also given to the lack of interest shown by the next generation in continuing the agricultural activities of the family. Low farm income and high workload were mentioned as reasons for this lack of interest. Further related reasons for land abandonment were the high farmer age and migration to the cities. Nevertheless, emotional bonds of the local youth to the agricultural parcels cultivated by their ancestors are

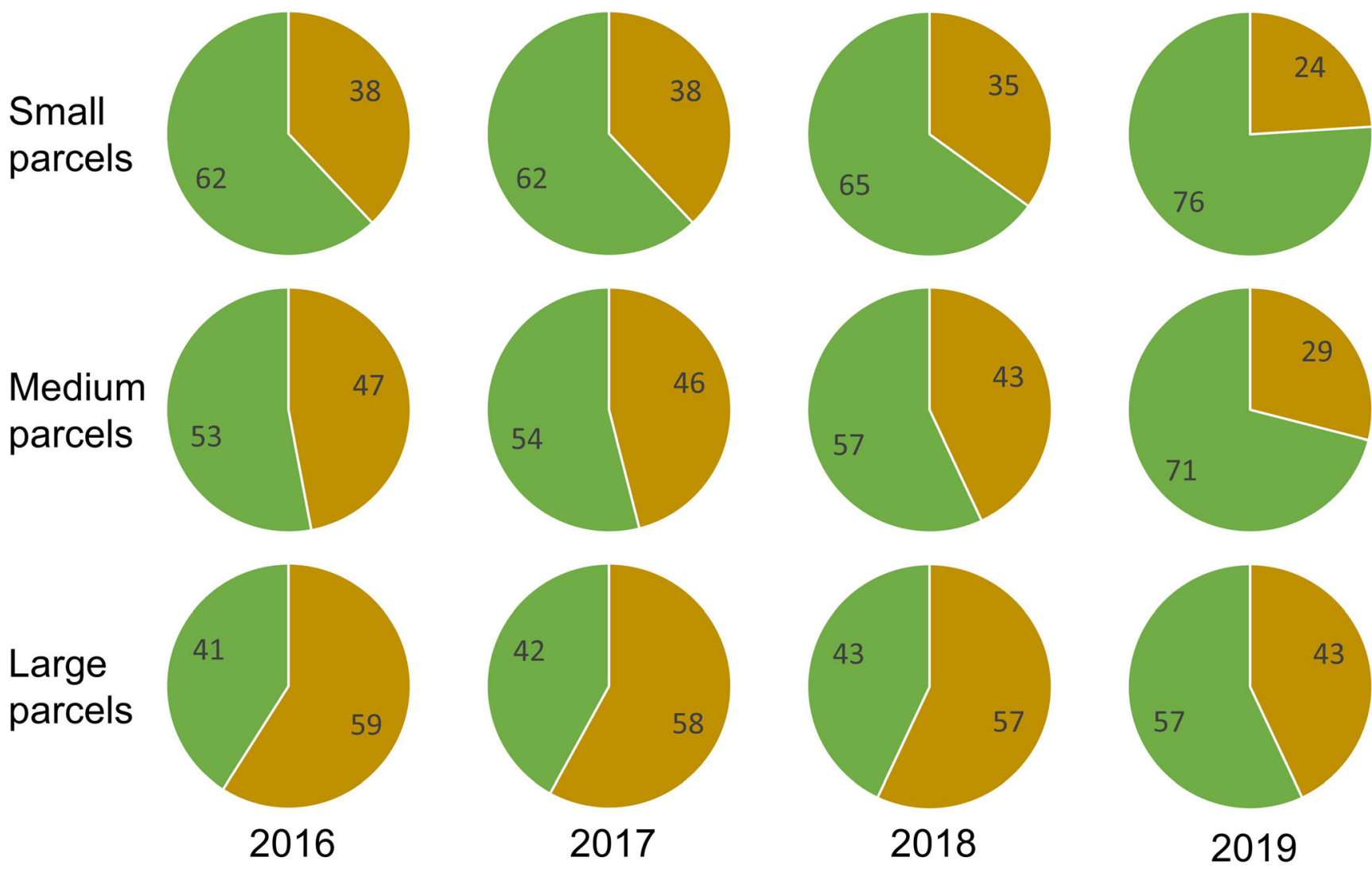

Fig. 6 Percentage of cultivated (green) and not-cultivated (brown) agricultural area according to parcel sizes in the Ricote Valley between 2016 and 2019. Small parcels contain parcels up to $556 \mathrm{~m}^{2}$, medium parcels $556-1533 \mathrm{~m}^{2}$, and large parcels contain an area larger than $1533 \mathrm{~m}^{2}$ 
Table 3 Percentage of total cultivated (C) and not-cultivated (NC) land covered by small, medium-sized, and large parcels in 2016 and 2019

\begin{tabular}{lcccrr}
\hline & \multicolumn{2}{l}{2016} & & \multicolumn{2}{l}{2019} \\
\cline { 2 - 3 } \cline { 5 - 6 } Parcel size category & $\mathrm{C}(\%)$ & $\mathrm{NC}(\%)$ & & $\mathrm{C}(\%)$ & $\mathrm{NC}(\%)$ \\
\hline Small & 6.94 & 3.36 & & 6.26 & 2.90 \\
Medium & 18.16 & 12.40 & & 17.72 & 10.69 \\
Large & 74.91 & 84.24 & & 76.02 & 86.40 \\
Total $(\%)$ & 100 & 100 & & 100 & 100 \\
\hline
\end{tabular}

strong, often preventing the sale of not-cultivated parcels, as explained by local experts, which reinforces land abandonment.

Finally, we discuss limitations within our mixed method approach. The land use classification using Sentinel data produced better results than using Lidar data. The accuracy of Sentinel data is $75.3 \%$. However, in this analysis, there are shortcomings in both detection methods, which produced classification errors during the detection of recently cultivated and recently abandoned parcels. Parcels, recently cultivated, were classified as not cultivated due to the high distance between small trees, and the high percentage of bare soil. Recently abandoned parcels were classified as cultivated, due to small changes only visible in the field or with very high-resolution images. Furthermore, there are various shortcomings using Lidar data. The most recent Lidar data is from 2016 (Instituto Geográfico Nacional 2019); thus, we were not able to research the most recent changes based on this data source. Moreover, the analysis with Lidar data is based on vegetation heights. Thus, it is more suitable for the detection of the cultivation status in tree plantations than for the detection of vegetable or cereal cultivation. Although the study area is dominated by tree cultivation, there are areas dominated by vegetable cultivation where a classification based on heights might not work. In order to assess the accuracy, we validated the land use classification in situ. Due to limited access to the agricultural parcels, we had to reduce the number of validation points to 81 .

While in this study the priority was given to quantitative methods, qualitative methods helped to deepen the understanding of the reasons for land abandonment and integrate local perspectives into the expert survey. This would not have been possible conducting a monomethod approach.

\section{Conclusion}

In this article, we examined the most recent trends of smallholder agriculture in the Ricote Valley, quantified the cultivation and abandonment of traditional orchards between 2016 and 2019, and investigated the reasons for abandonment using a mixed method approach.

We observed a high percentage of agricultural land abandonment for terraces detected within the traditional orchards of the Ricote Valley. In 2016, 56.33\% of the detected terraces in this agricultural area were classified as not cultivated. This trend of abandonment has been decreasing recently, with only $39.94 \%$ of the detected terraces in this agricultural area being classified as not cultivated in 2019.

In the study area, small parcels were cultivated to a higher percentage than large or medium-sized parcels. This could be related to small parcels being cultivated by family farms, and agriculture not representing their main income source. In fact, small parcels ensure food security and tend to be less vulnerable to price volatility. Nevertheless, like in most European regions, the agricultural area covered by small and mediumsized parcels decreased between 2016 and 2019, while the agricultural area covered by large parcels expanded.

In addition to a GIS-based top-down approach, we used participant observation and an expert survey as place-based research methods. This mixed method design contributed to a more complete picture of land abandonment in the study area. According to the experts, there are multiple important reasons for the abandonment of agriculture in the Ricote Valley: low income of farmers and market competition with large-scale industrial agriculture in the surrounding area; land fragmentation, which results in higher transaction costs for farmers; lack of interest in continuing agricultural activities among young generations; lack of modernization; and finally strong emotional bonds to the land, which have prevented the transfer of agricultural parcels and may further explain land abandonment.

We emphasize that a paradigm shift in agriculture is needed to identify alternative pathways for the recovery of abandoned and degraded lands. Alternative pathways should be based on integrating social, ecological, and economic needs. Such an integrated approach should be supported by dedicated policies at the European, national, and local levels. Agricultural subsidies should be distributed following the principle of public money for public services, promoting multifunctional agriculture. More support for young farmers, for innovative farms, and for a transition to organic agriculture is needed, addressing the low income of farmers and the lack of interest in farming activities among young generations. For example, promoting farms that use agroecological practices, sell directly to urban customers and process their products in-house, can contribute to the regeneration of degraded and abandoned lands, the reinforcement of local food chains, and the revival of local employment. A reformed agricultural policy can make one of the greatest contributions to protecting biodiversity, mitigating the effects of climate change, reducing rural exodus, and supporting social innovation. 
We are going to continue our research in Spain, investigating the regeneration of abandoned and degraded lands. Therefore, we will explore the role of agroecological practices for a multifunctional agriculture. We will focus on alternative water and land management pathways, which integrate traditional agroecological knowledge, practices, and technologies from Mediterranean semi-arid regions.

Acknowledgments We would like to thank Dr. José María García Avilés for the reliable support during the whole research process in the Ricote Valley and two external reviewers for their helpful comments. This research was funded by Friedrich-Ebert-Foundation and in part supported by the CLICCS Cluster of Excellence funded by the German Research Foundation.

Funding Open Access funding enabled and organized by Projekt DEAL.

Open Access This article is licensed under a Creative Commons Attribution 4.0 International License, which permits use, sharing, adaptation, distribution and reproduction in any medium or format, as long as you give appropriate credit to the original author(s) and the source, provide a link to the Creative Commons licence, and indicate if changes were made. The images or other third party material in this article are included in the article's Creative Commons licence, unless indicated otherwise in a credit line to the material. If material is not included in the article's Creative Commons licence and your intended use is not permitted by statutory regulation or exceeds the permitted use, you will need to obtain permission directly from the copyright holder. To view a copy of this licence, visit http://creativecommons.org/licenses/by/4.0/.

\section{References}

Alonso-Sarría F, Martínez-Hernández C, Romero-Díaz A, CánovasGarcía F, Gomariz-Castillo F (2016) Main environmental features leading to recent land abandonment in Murcia region (Southeast Spain). Land Degrad Develop 27:654-670. https://doi.org/10. 1002/ldr.2447

Altieri MA, Nicholls CI (2012) Agroecology scaling up for food sovereignty and resiliency. In: Lichtfouse E (ed) Sustainable Agriculture Reviews. Springer Netherlands, Dordrecht, pp 1-30

Balbo AL, Gómez-Baggethun E, Salpeteur M, Puy A, Biagetti S et al (2016) Resilience of small-scale societies: a view from drylands. Ecol Soc 21. https://doi.org/10.5751/ES-08327-210253

Balbo AL, García Avilés JM, Hunink J, Alcón F, Palenzuela Cruz JE et al (2020) Challenges and opportunities for historical irrigated agricultural systems in Mediterranean regions. Technical, cultural, and environmental assets for sustainable rural development in Ricote (Murcia, Spain). In: Brzoska M, Scheffran J (eds) Climate change, security risks, and violent conflicts. Essays from Integrated Climate Research in Hamburg. Hamburg University Press, Hamburg, 143161

Barthel S, Crumley C, Svedin U (2013) Bio-cultural refugiasafeguarding diversity of practices for food security and biodiversity. Glob Environ Chang 23:1142-1152. https://doi.org/10.1016/j. gloenvcha.2013.05.001

Bendetti R, Rossini P, Taddei R (1994) Vegetation classification in the middle Mediterranean area by satellite data. Int J Remote Sens 15: 583-596. https://doi.org/10.1080/01431169408954098

Bentley JW (1987) Economic and ecological approaches to land fragmentation: in defense of a much-maligned phenomenon. Annu
Rev Anthropol 16:31-67. https://doi.org/10.1146/annurev.an.16. 100187.000335

Bernard B, Lux A (2017) How to feed the world sustainably: an overview of the discourse on agroecology and sustainable intensification. Reg Environ Chang 17:1279-1290. https://doi.org/10.1007/s10113-0161027-y

Blondel J (2006) The 'design' of Mediterranean landscapes: a millennial Story of humans and ecological systems during the historic period. Hum Ecol 34:713-729. https://doi.org/10.1007/s10745-006-9030-4

Bravo Sánchez JM (2018) Paisaje Rural y Patrimonio Hidráulico, referentes señeros presentes en la cultura rural del valle de Ricote (España) y de la Zona Central de Chile. Dissertation, Universidad de Murcia

Chemnitz C (2019) Agriculture Atlas. Facts and figures on EU farming policy. Heinrich-Böll-Stiftung, Friends of the Earth Europe, BirdLife International, Berlin

Conrad O, Bechtel B, Bock M, Dietrich H, Fischer E et al (2015) System for Automated Geoscientific Analyses (SAGA) v. 2.1.4. Geosci Model Dev 8:1991-2007. https://doi.org/10.5194/gmd-8-19912015

Cramer W, Guiot J, Fader M, Garrabou J, Gattuso JP et al (2018) Climate change and interconnected risks to sustainable development in the Mediterranean. Nature Clim Change 8:972-980. https://doi.org/10. 1038/s41558-018-0299-2

Crecente R, Alvarez C, Fra U (2002) Economic, social and environmental impact of land consolidation in Galicia. Land Use Policy 19:135147. https://doi.org/10.1016/S0264-8377(02)00006-6

Endenburg S, Mitchell GW, Kirby P, Fahrig L, Pasher J et al (2019) The homogenizing influence of agriculture on forest bird communities at landscape scales. Landsc Ecol 34:2385-2399. https://doi.org/10. 1007/s10980-019-00895-8

European Commission (2019) Statistical Factsheet Spain. https://ec. europa.eu/info/food-farming-fisheries/farming/facts-and-figures/ markets/production/production-country/statistical-factsheets. Accessed 05 May 2020

Freibauer A, Mathhijs E, Brunori G, Damianova Z, Faroult E et al (2011) Sustainable food consumption and production in a resourceconstrained world. EuroChoices:10. https://doi.org/10.5755/j01. erem.58.4.994

García Avilés JM (2000) El Valle de Ricote: Fundamentos económicos de la encomienda santiaguista. Real Academia Alfonso X el Sabio y el Ayuntamiento de Ricote, Murcia

García Avilés JM (2014) La huerta de Ricote. Memoria gráfica del esfuerzo de un pueblo por no perder su fuente tradicional de ingresos. https://doi.org/10.13140/2.1.1575.6166

German National Academy of Sciences Leopoldina, acatech - National Academy of Science and Engineering, Union of German Academies of Sciences and Humanities (2018) Species decline in the agricultural landscape: What do we know and what can we do? https://doi. org/10.13140/RG.2.2.10671.07842

Gil Meseguer E (2014) Paisajes culturales del regadío tradicional e histórico en la Vega Alta de Segura. In: Sanchis-Ibor C, PalauSalvador, G. Mangue Alférez, I., Martínez-Sanmartín LP (eds) Irrigation, Society and Landscape: Tribute to Thomas F. Glick. Editorial Universitat Politècnica de València, pp. 856-867

Gómez-Baggethun E, Corbera E, Reyes-García V (2013) Traditional ecological knowledge and global environmental change: research findings and policy implications. Ecol Soc 18:72. https://doi.org/ 10.5751/ES-06288-180472

Hathaway MD (2016) Agroecology and permaculture: addressing key ecological problems by rethinking and redesigning agricultural systems. J Environ Stud Sci 6:239-250. https://doi.org/10.1007/ s13412-015-0254-8

Heider K, Rodriguez Lopez JM, García Avilés JM, Balbo AL (2018) Land fragmentation index for drip-irrigated field systems in the 
Mediterranean: a case study from Ricote (Murcia, SE Spain). Agric Syst 166:48-56. https://doi.org/10.1016/j.agsy.2018.07.006

IAASTD (2009) Agriculture at a crossroads. The global report of the International Assessment of Agricultural Knowledge, Science, and Technology. Island Press, Washington, DC.

Instituto Geográfico Nacional (2019) Centro de Descargas. https://www. ign.es/web/ign/portal. Accessed 5 Dec 2019

IPES-FOOD (2016) From uniformity to diversity: a paradigm shift from industrial agriculture to diversified agroecological systems. International Panel of Experts on Sustainable Food systems. http:// www.ipes-food.org/. Accessed 12 Oct 2020

Jouzi Z, Azadi H, Taheri F, Zarafshani K, Gebrehiwot K et al (2017) Organic farming and small-scale farmers: main opportunities and challenges. Ecol Econ 132:144-154. https://doi.org/10.1016/j. ecolecon.2016.10.016

Kuckartz U (2014) Mixed methods: Methodologie, Forschungsdesigns und Analyseverfahren. Springer, Wiesbaden

Kurz P (2018) Between smallholder traditions and "ecological modernisation" - agricultural transformation, landscape change and the cap in Austria 1995-2015. European Countryside 10:158-179. https:// doi.org/10.2478/euco-2018-0010

Lasanta T, Errea MP, Nadal-Romero E (2017a) Traditional agrarian landscape in the Mediterranean Mountains. A regional and local factor analysis in the Central Spanish Pyrenees. Land Degrad Dev 28. https://doi.org/10.1002/ldr.2695

Lasanta T, Arnáez J, Pascual N, Ruiz-Flaño P, Errea MP et al (2017b) Space-time process and drivers of land abandonment in Europe. Catena 149:810-823. https://doi.org/10.1016/j.catena.2016.02.024

Lefebvre M, Espinosa M, Gomez y Paloma S, Paracchini ML, Piorr A et al (2015) Agricultural landscapes as multi-scale public good and the role of the common agricultural policy. J Environ Plan Manag 58:2088-2112. https://doi.org/10.1080/09640568.2014.891975

Lillesand TM, Kiefer RW, Chipman JW (2004) Remote sensing and image interpretation, 5th edn. John Wiley, New York

Lomba A, Moreira F, Klimek S, Jongman RHG, Sullivan C et al (2019) Back to the future: rethinking socioecological systems underlying high nature value farmlands. Front Ecol Environ 18:36-42. https:// doi.org/10.1002/fee. 2116

Ministerio de Hacienda (2020) Sede Electrónica del Catastro. https:// www.sedecatastro.gob.es/. Accessed 20 Mar 2020

Otero I, Marull J, Tello E, Diana GL, Pons M et al (2015) Land abandonment, landscape, and biodiversity: questioning the restorative character of the forest transition in the Mediterranean. Ecol Soc 20. https://doi.org/10.5751/ES-07378-200207

Plieninger T, Höchtl F, Spek T (2006) Traditional land-use and nature conservation in European rural landscapes. Environ Sci Pol 9:317321. https://doi.org/10.1016/j.envsci.2006.03.001

Puy A, Balbo AL (2013) The genesis of irrigated terraces in al-Andalus. A geoarchaeological perspective on intensive agriculture in semiarid environments (Ricote, Murcia, Spain). J Arid Environ 89:4556. https://doi.org/10.1016/j.jaridenv.2012.10.008

Puy A, Garcia Aviles JM, Balbo AL, Keller M, Riedesel S et al (2016) Drip irrigation uptake in traditional irrigated fields: the edaphological impact. J Environ Manag. https://doi.org/10.1016/j. jenvman.2016.07.017

Región de Murcia (2017) Red Natura 2000: API013 Sierras de Ricote y la Navela. http://www.murcianatural.carm.es. Accessed 25 Feb 2020

Rey Benayas J, Martins A, Nicolau JM, Schulz JJ (2007) Abandonment of agricultural land: an overview of drivers and consequences. $\mathrm{CAB}$ Rev 2. https://doi.org/10.1079/PAVSNNR20072057

Reynolds HL, Smith AA, Farmer JR (2014) Think globally, research locally: paradigms and place in agroecological research. Am J Bot 101:1631-1639. https://doi.org/10.3732/ajb.1400146

See L, Fritz S, Perger C, Schill C, McCallum I et al (2015) Harnessing the power of volunteers, the internet and Google Earth to collect and validate global spatial information using Geo-Wiki. Technol Forecast Soc Change 98:324-335. https://doi.org/10.1016/j. techfore.2015.03.002

Spanó A, Sammartano G, Calcagno Tunin F, Cerise S, Possi G (2018) GIS-based detection of terraced landscape heritage: comparative tests using regional DEMs and UAV data. Appl Geomat 8:1-21. https://doi.org/10.1007/s12518-018-0205-7

Springmann M, Clark M, Mason-D'Croz D, Wiebe K, Bodirsky BL et al (2018) Options for keeping the food system within environmental limits. Nature 562:519-525. https://doi.org/10.1038/s41586-0180594-0

Story M, Congalton RG (1986) Accuracy assessment: a user's perspective. Photogrammetric Engineering \& Remote Sensing 52:397-399

Tarolli P, Preti F, Romano N (2014) Terraced landscapes: from an old best practice to a potential hazard for soil degradation due to land abandonment. Anthropocene 6:10-25. https://doi.org/10.1016/j. ancene.2014.03.002

Thomas S (2019) Ethnografie. Eine Einführung. Springer, Wiesbaden

USGS (2019) EarthExplorer. https://earthexplorer.usgs.gov/. Accessed 5 Dec 2019

van der Zanden EH, Carvalho-Ribeiro SM, Verburg PH (2018) Abandonment landscapes: user attitudes, alternative futures and land management in Castro Laboreiro, Portugal. Reg Environ Chang 18: 1509-1520. https://doi.org/10.1007/s10113-018-1294-x

Vicente-Serrano SM, Lopez-Moreno JI, Beguería S, Lorenzo-Lacruz J, Sanchez-Lorenzo A et al (2014) Evidence of increasing drought severity caused by temperature rise in southern Europe. Environ Res Lett 9:044001. https://doi.org/10.1088/1748-9326/9/4/044001

WBGU (2011) World in transition - A social contract for sustainability. German Advisory Council on Global Change, Berlin

Zagaria C, Schulp CJE, Kizos T, Verburg PH (2018) Perspectives of farmers and tourists on agricultural abandonment in East Lesvos, Greece. Reg Environ Chang 18:1467-1479. https://doi.org/10. 1007/s10113-017-1276-4

Zaragozí BM, Navarro JT, Ramón A, Rodríguez-Sala JJ (2011) A study of drivers for agricultural land abandonment using GIS and data mining techniques. WIT Trans Ecol Environ 144:363-374. https:// doi.org/10.2495/ECO110321

Publisher's note Springer Nature remains neutral with regard to jurisdictional claims in published maps and institutional affiliations. 